\title{
Concepções de Pobreza: Um Convite à Discussão Psicossocial
}

\author{
James Ferreira Moura Jr. ${ }^{1}$ \\ Programa de Pós-Graduação em Psicologia da Universidade Federal do Rio Grande do Sul, \\ Porto Alegre, Rio Grande do Sul, Brasil \\ Elívia Camurça Cidade \\ Departamento de Psicologia da Universidade Estadual do Ceará, Fortaleza, Ceará, Brasil \\ Verônica Morais Ximenes \\ Programa de Pós-Graduação em Psicologia da Universidade Federal do Ceará, \\ Fortaleza, Ceará, Brasil \\ Jorge Castellá Sarriera \\ Programa de Pós-Graduação em Psicologia da Universidade Federal do Rio Grande do Sul, \\ Porto Alegre, Rio Grande do Sul, Brasil
}

\section{Resumo}

Este artigo objetiva analisar as visões da unidimensionalidade e da multidimensionalidade da pobreza a fim de incorporar dimensões psicossociais que contribuam para análise da complexidade desse fenômeno. A pobreza, geralmente, está baseada na tendência unidimensional monetária de conceituação e mensuração, restringindo a análise a linhas de pobreza. Há, então, o paradigma multidimensional da Abordagem das Capacitações que amplia a concepção de pobreza. É incorporada a centralidade da autonomia e da liberdade do indivíduo no exercício de suas capacitações e seus funcionamentos como elementos de definição da pobreza. No entanto, em sua perspectiva prática, a Abordagem das Capacitações situa-se geralmente na identificação de questões concretas de saúde, habitação e padrão de vida relacionada à pobreza. Assim, identifica-se a necessidade de incorporação de dimensões psicossociais que contribuam para expansão do crítico entendimento desse fenômeno e abarquem aspectos subjetivos, negativos e positivos no tocante às estratégias de enfrentamento desenvolvidas pelos pobres. Nesse sentido, são propostas as análises do bem estar pessoal, do senso de comunidade, das práticas discriminatórias e do fatalismo das pessoas em situação de pobreza. Portanto, analisa-se a necessidade e o compromisso da ciência psicológica na elaboração de conhecimentos para a ampliação de entendimento desse fenômeno.

Palavras-chave: Pobreza, Psicologia, psicossocial.

\section{Conceptions of Poverty: An invitation for a Psychosocial Discussion}

\begin{abstract}
This article aims to analyze the views of unidimensionality and multidimensionality of poverty in order to incorporate psychosocial dimensions that contribute to analysis of the complexity of this phenome-

Endereço para correspondência: Universidade Federal do Rio Grande do Sul, Instituto de Psicologia, Rua Ramiro Barcelos, 2600, Sala 122, Santa Cecília, Porto Alegre, RS, Brasil 90035-003. E-mail: jamesferreirajr@, gmail.com, elivia_nucom@yahoo.com.br, vemorais@yahoo.com.br e jorgesarriera@gmail.com Agradece-se a Coordenação de Aperfeiçoamento de Pessoal de Nível Superior (CAPES) pelo financiamento.
\end{abstract}


non. Poverty is generally based on monetary unidimensional of the conceptualization and measurement, restricting the analysis to poverty lines. There is, then, the multidimensional paradigm of the Capabilities Approach that extends the concept of poverty. It is built into the centrality of the autonomy and freedom of the individual in the exercise of their capabilities and functionings as elements of definition of poverty. However, in its practical perspective, the Capabilities approach is located generally in the identification of specific health issues, housing and living standards related to poverty. So, identifies the need to incorporate psychosocial dimensions that contribute to expansion of the critic understanding of this phenomenon and cover subjective, negative and positive aspects with regard to coping strategies developed by the poor. It is proposed to personal well-being, analysis of the sense of community, of discriminatory practices and fatalism of those in poverty. Therefore, it analyses the need and commitment of psychological science in developing knowledge to increase understanding of this phenomenon.

Keywords: Poverty, Psychology, psychosocial.

\section{Las Concepciones de la Pobreza: Um Invitación a la Discusión Psicosocial}

\section{Resumen}

Este artículo tiene como objetivo analizar las visiones de unidimensionalidad y multidimensionalidad de la pobreza con el fin de incorporar las dimensiones psicosociales que contribuyen al análisis de la complejidad de este fenómeno. La pobreza general se basa en la tendencia unidimensional monetaria de conceptualización y medición, limitando el análisis a las líneas de pobreza. Hay, pues, el paradigma multidimensional del enfoque de las capacidades que se extiende al concepto de pobreza. Se incorpora la importancia de la autonomía y de la libertad del individuo en el ejercicio de sus capaciotaciones y sus funcionamientos como elementos de la definición de la pobreza. Sin embargo, en una perspectiva práctica, el enfoque de las capacitaciones es por lo general para identificar los problemas concretos de las condiciones de salud, la vivienda y de vida relacionados con la pobreza. Así, se identifica la necesidad de incorporar las dimensiones psicosociales que contribuyen para ampliar la comprensión crítica de este fenómeno y cubren aspectos subjetivos, positivos y negativos con respecto a las estrategias de supervivencia desarrolladas por los pobres. Se propone analizar el bienestar personal, el sentido de comunidad, las prácticas discriminatorias y el fatalismo de las personas en situación de pobreza. Por lo tanto, $\mathrm{Se}$ analiza la necesidad y el compromiso de la ciencia psicológica en el desarrollo del conocimiento para la ampliación de la comprensión de este fenómeno

Palabras clave: Pobreza, Psicología, psicosocial.

As carências monetárias, definidas em termos da deficiência de renda e de poder de consumo dos indivíduos, foram utilizadas para justificar a distinção entre os ricos e os não ricos durante longo período. Este olhar se demonstra insuficiente para dar conta das experiências de pobreza que envolvem privações sob mais variados aspectos relacionados à saúde, à educação, a políticas de geração de emprego e renda, ao esporte e ao lazer. Igualmente, a identificação da pobreza somente amparada pela falta de dinheiro é portadora de elementos ideológicos, políticos e psicológicos específicos e limitados.
A inclusão na pauta da agenda pública da erradicação da pobreza em termos de redistribuição de renda está centralizada no aspecto monetário. Para se ter uma idéia, em 2012 estimava-se que 3,4\% dos 190 milhões de brasileiros viviam em pobreza extrema ("Brasil comemora redução da pobreza extrema", 2012), ou seja, possuíam renda per capita familiar de até $\mathrm{R} \$ 70,00$. A elaboração do Plano Brasil Sem Miséria se configura como uma estratégia governamental que objetiva elevar a renda e as condições de bem estar da população brasileira (Ministério do Desenvolvimento Social e Combate à Fome [MDS], 2012). 
Esta iniciativa prevê um incremento financeiro ao Programa Bolsa Família, caracterizado como ação governamental de transferência direta de renda vinculada ao MDS. Assim, segundo dados do Governo Brasileiro, ocorreu a retirada de 22 milhões de pessoas da extrema pobreza (MDS, 2013). Contudo, a redistribuição de renda representa somente o início de um longo e difícil processo (Barros, Carvalho, \& Franco, 2007).

Portanto, é necessário conceber a pobreza em sua complexidade, pois ela é constituída também de fatores sociais, políticos e simbólicos. Moura (2012) afirma que às pessoas pobres são geralmente impetradas variadas formas de discriminação, sendo concebidas como criminosas, violentas, culpadas pela sua situação de pobreza, vagabundas, sujas, doentes e causadoras de mazelas sociais. A pobreza, então, funciona como uma estratégia de manutenção do status quo. Há a uma série de práticas, valores e crenças que delimitam o modo de viver dos pobres, desenvolvendo uma forma específica de identidade que é "negada, sofrida, desamparada, frágil, e também violenta" (Góis, 2008, p. 60). Este último autor identifica que essa rede ideológica de opressão aos empobrecidos causa atitudes de conformismo, de passividade, de violência e de desagregação familiar e comunitária. Cidade, Moura e Ximenes (2012) estabelecem que geralmente a estratégia de sobrevivência encontrada pelos empobrecidos para enfrentar essa realidade opressora de pobreza é o estabelecimento de atitudes conformistas, em que não há esperança sobre as possibilidades de mudança dessas condições.

Com isso, para consolidação de uma estratégia de erradicação efetiva e abrangente, são necessárias ações singulares e investimentos específicos, que considerem as implicações práticas e as origens ideológicas da pobreza (Accorssi, Scarparo, \& Guareschi, 2012). Um passo fundamental para este processo de mudança está na adoção de perspectivas multidimensionais da pobreza. No entanto, também é imprescindível a compreensão das dimensões psicossociais que estão relacionadas a esse fenômeno. Dessa forma, é necessário discutir as visões da unidimen- sionalidade e multidimensionalidade da pobreza a fim de incorporar essas dimensões psicossociais que contribuam para análise da complexidade desse problema social.

Assim, a perspectiva unidimensional monetária da pobreza será apresentada em termos das linhas que a compõem. Já a compreensão multidimensional, será baseada na Abordagem das Capacitações, entendida como uma teoria do desenvolvimento humano que concebe a pobreza como um fator que pode prejudicar o exercício das liberdades dos sujeitos (Sen, 2000). Em seguida, realizam-se também, mediante revisão crítica da literatura, apontamentos para refinamentos da Abordagem das Capacitações a partir da inserção de dimensões psicossociais imprescindíveis para o entendimento crítico da pobreza.

\section{A Perspectiva Unidimensional Monetária de Pobreza}

A perspectiva monetária e unidimensional da pobreza emerge como o caminho de definição deste fenômeno ao estabelecer a deficiência de renda como indicador de pobreza. Assim, são definidas linhas de pobreza que identificariam a existência dessa realidade. Comim e Bagolin (2002), contudo, afirmam que o perdurar deste pensamento somente é possível porque faltam estatísticas sociais, e há uma dificuldade de mensuração e de agregação de outras dimensões aos indicadores monetários da pobreza.

Dentre as diferentes estratégias de identificação da pobreza como deficiência monetária a partir de linhas, destacam-se: absoluta, relativa, administrativa e subjetiva (Soares, 2009). A concepção de pobreza absoluta se refere a um parâmetro monetário independente do padrão financeiro de uma determinada sociedade. É utilizada a nível mundial para mensurar a pobreza, sendo a abordagem mais usada na América Latina (Comim \& Bagolin, 2002). Essa identificação universal da pobreza pela sua capacidade de consumo baseada na renda está relacionada à aquisição de alimentação mínima para sobrevivência. 
Esse valor absoluto de referência de pobreza é \$ 2,00 dólares por dia (Organização das Nações Unidas no Brasil [ONUBR], 2011). Ele foi criado pelo Banco Mundial para o estabelecimento da linha da pobreza, sendo obtido a partir do cálculo do valor médio das linhas de pobreza relativa dos países pesquisados em relação com o poder de compra dos consumidores e com a conversão da moeda local em dólares. No entanto, essa única referência da pobreza com base em dólares recebe muitas críticas, porque o consumo generalizado dos habitantes dos países entra no cálculo da abordagem, levando em conta tanto os gastos dos ricos, que são bem maiores, como os dos sujeitos em condições de pobreza. Igualmente, aponta-se criticamente pela dificuldade de comparação de um índice único de pobreza entre países tão diversos e pela adoção na Europa dos índices de pobreza relativa no pós-guerra (Soares, 2009).

Então, a linha de pobreza relativa se refere ao padrão de referência a partir da média ou mediana de consumo de uma sociedade ou de um grupamento, abordando o sujeito em condições de pobreza como aquele que está abaixo desse parâmetro local. Ela está relacionada a uma média de referência da região (Comim \& Bagolin, 2002; Soares, 2009). É estabelecida um valor regional em que as pessoas situadas abaixo deste padrão são consideradas pobres (Laderchi, Saith, \& Stewart, 2003). Dessa maneira, a referência para a pobreza passa a estar em função da desigualdade de renda observada em determinado local. É importante destacar que há, igualmente, a linha de pobreza de abordagem dual, que envolve a combinação das perspectivas absoluta e relativa (Picolotto, 2006).

A pobreza também pode ser entendida por linhas administrativas. A utilização dessa linha usualmente ocorre por abandono da perspectiva absoluta e relativa devido à falta de rigor metodológico consensual. Assim, essa linha pode ser estipulada de forma arbitrária por instâncias governamentais e outros órgãos da federação, que optam por referenciar a pobreza por meio do estabelecimento de critérios próprios. Dessa forma, há uma grande variedade de linhas administrativas. Por exemplo, no Brasil, o valor de até $\mathrm{R} \$ 120,00$ reais por pessoa representava o parâmetro para ter acesso ao Programa Bolsa Família. Já o valor de $1 / 4$ do salário mínimo é a referência para ter acesso ao Benefício de Prestação Continuada do Ministério da Previdência Social. Geralmente, essas linhas administrativas são variadas e utilizadas co- mo referência para distribuição de recursos governamentais (Soares, 2009).

Outra forma de mensuração é a partir do estabelecimento de uma linha subjetiva que amplia a concepção de pobreza baseada estritamente na renda. É o sujeito, por meio de sua vivência no contexto histórico e cultural, que define o parâmetro monetário que configurará a situação de pobreza (Picolotto, 2006; Soares, 2009). Porém, há problemas com essa abordagem, porque as expectativas dos indivíduos podem ser um fator muito significativo no resultado final da mensuração da pobreza. É importante salientar que, a partir do enfoque específico que é abordada a pobreza em políticas públicas ou programas institucionais, há a delimitação do público atendido, determinando "quais indivíduos serão considerados pobres, quais e quantas pessoas serão beneficiadas por programas de combate à pobre$\mathrm{za}$, de que forma e em que magnitude esses indivíduos serão atendidos" (Andrade, 2011, p. 10). Ou seja, essas formas de identificação da pobreza ocasionam grandes repercussões na vida das pessoas pobres. Focalizar a pobreza apenas como uma insuficiência monetária é desprezar outros fatores que são constituintes do bem-estar do indivíduo; é ignorar heterogeneidade de sujeitos, de contextos sociais, de culturas e de liberdades pessoais (Sen, 2000). Por isso, este trabalho situa-se no âmbito da abordagem multidimensional da pobreza, compreendendo esse fenômeno em sua constituição social, política e ideológica. O ser humano, então, passa a ser concebido de forma abrangente e integral.

\section{A Emergência do Olhar Multidimensional Sobre a Pobreza}

As estratégias de redução da pobreza, para serem eficientes, necessitam avançar em direção ao reconhecimento das necessidades peculiares 
dos indivíduos inseridos em um dado contexto social e cultural, possibilitando a inserção de novos elementos para uma leitura ampliada desse fenômeno. Este processo de expansão conceitual anuncia também transformações metodológicas nas alternativas visualizadas para mudança desta realidade. Permite-se, assim, o avanço em direção a um enfoque multidimensional da pobreza. A discussão e a defesa das Abordagens Multidimensionais para a compreensão da pobreza foi alavancada a partir da década de 1970, tendo como objetivo perceber a pobreza não somente vinculada a fatores monetários, mas como âmbito social (Lacerda, 2009). As Abordagens Multidimensionais da pobreza não excluem a abordagem monetária, mas acrescentam uma perspectiva mais abrangente e contextualizada a esta segunda. Sob essa perspectiva multidimensional, há a Abordagem das Capacitações (AC), prisma de análise da pobreza escolhida para embasar essa produção, e que será, nas páginas que seguem, representada pelas inicias AC. Ela foi criada por Armatya Kumar Sen, ganhador do premio Nobel de Economia em 1998.

A Abordagem das Capacitações concebe o ser humano como dotado de potencialidades que são contextuais, sociais, culturais e pessoais. O indivíduo é concebido como ativo na transformação da realidade, fundamentando-se "nos estados mentais, como felicidade e satisfação dos desejos, e nos bens primários com as teorias baseadas em renda, gastos, consumos ou necessidades básicas" (Picolotto, 2006, p. 34). Segundo Sen (2000), a AC baseia-se em Aristóteles na centralidade da liberdade como uma questão substantiva; em Adam Smith no foco das condições de vida específicas para as necessidades humanas; e em Marx na autonomia em relação à atividade.

Dessa maneira, a AC arquiteta que há indivíduos que estão em situação de maior adversidade, necessitando de ações específicas (Alkire, 2005). Ela aponta a centralidade da estrutura social para o entendimento das condições de vida das pessoas, tendo como foco a elaboração de medidas avaliativas e de políticas prospectivas baseadas na expansão das liberdades (Alkire \& Deunelin, 2009). Segundo Moura (2012), há nessa abordagem a compreensão multidimensional e processual para entender a pobreza, apontando ainda de forma incipiente questões históricas, políticas, ideológicas e psicológicas em sua constituição. Essa abordagem tem suas bases estruturadas no incentivo e na defesa de novas possibilidades de existência dos seres humanos frente à estrutura social que, geralmente, cerceia seu modo de vida.

$\mathrm{Na} \mathrm{AC}$, os seres humanos são concebidos como portadores de funcionamentos, que são relativos ao que a pessoa pode fazer e ao que a pessoa pode ser em diferentes dimensões da vida, ou seja, refere-se às realizações dos indivíduos (Alkire, 2005; Crespo \& Gurovitz, 2000; Sen, 2000).

Esses funcionamentos são as atividades e os estados que constituem o bem estar da pessoa, estando também relacionados às formas de utilização dos recursos disponíveis ao indivíduo (Cohen, 1996; Sen, 2000). Já as capacitações seriam as liberdades dos indivíduos de ser capaz ou de realizar, permitindo à pessoa ter, alcançar ou mudar seus funcionamentos (Kakwani, 2006, apud McKinley, 2008; Kerstenetsky, 2000). Essas capacitações, que contribuem para o bem estar do indivíduo, fornecem as liberdades substantivas que possibilitam à pessoa modificar seus funcionamentos. Elas, então, seriam combinações de funcionamentos de que a pessoa pode ser portadora e evidenciam a liberdade de escolha do indivíduo (Sen, 2000). Nesse sentido, a concepção de desenvolvimento humano da AC está alicerçada na vivência da liberdade pelo sujeito.

Com isso, o fato de não ter dinheiro repercute em formas específicas de reconhecimento de si mesmo e da sociedade, estruturando igualmente formas singulares de "ser" e de "fazer" das pessoas pobres. Assim, a pobreza é concebida por Sen $(1980,1996)$ como a privação de capacitações básicas, ou seja, não satisfazendo funcionamentos imprescindíveis à sobrevivência, como estar nutrido de forma satisfatória, estar saudável sem a eminência de doenças ou de morte precoce, ser feliz, ser autorrespeitado e conviver livremente na dinâmica comunitária. Dessa maneira, a AC, baseada na perspectiva de 
Sen, tem uma tendência metaética constituída de um âmbito filosófico e epistemológico em que não é possível estabelecer uma lista predeterminada de capacitações universais, enfocando que o entendimento da pobreza parte do contexto. É evidenciado que cada pessoa é considerada capaz de alcançar minimamente seus funcionamentos, assim como há a centralidade da estrutura social no desenvolvimento das capacitações e das suas privações desenvolvidas pela pobreza. Também é apontado que são necessárias políticas específicas junto com a atuação dos cidadãos para enfrentamento da pobreza. São indicadas igualmente formas de mensuração que abordem a avaliação dos fatores pessoais, dos espaços e das circunstâncias sociais envolvidas na situação de pobreza (Chiappero-Martinetti \& Moroni, 2007).

Dessa maneira, segundo Sen (1996), a identificação da privação de capacitações básicas contextuais é concebida como uma eficiente estratégia para mensuração e diagnóstico da pobreza, sendo, para o Programa das Nações Unidas para o Desenvolvimento (PNDU, 2010), o Índice de Pobreza Multidimensional o instrumento mais recente e consensual para essa mensuração. No entanto, as dimensões criadas para mensurar a pobreza no nível multidimensional nesse Índice estão restritas a padrões de vida envolvendo a renda, a habitação, a escolaridade e a saúde (PNUD, 2010). Assim, a multidimensionalidade da pobreza é dificilmente alcançada em sua perspectiva abrangente e complexa na maioria dos estudos desenvolvidos (Avila, Bagolin, \& Comim, 2012). Igualmente, acrescenta-se que falta uma discussão crítica e social sobre as origens e manutenção da pobreza, como uma estratégia de legitimação e permanência da desigualdade social.

O próprio PNUD (2010) já indica algumas dimensões necessárias para compreensão da pobreza, como "o trabalho informal, a capacitação, a segurança em relação à violência e as relações humanas" (p. 99). Alkire (2007) enfatiza também que é imprescindível analisar a pobreza a partir da qualidade do trabalho, da segurança física, do empoderamento, do bem estar psicológico e subjetivo e da capacidade de viver sem sentir ver- gonha. A partir dessas considerações, observa-se que a compreensão multidimensional da pobreza está ainda em seu processo de construção, sendo premente acrescentar dimensões psicossociais e críticas para entendimento ampliado da pobreza.

\section{A Importância das Dimensões Psicossociais na Compreensão Multidimensional da Pobreza}

A Abordagem Multidimensional da Pobreza aborda as dimensões ampliadas de saúde, de educação e de padrão de vida, porém não abrange de forma crítica e estrutural dimensões psicológicas e sociais da vida em condições de pobreza. Esses aspectos estão manifestos em comportamentos, ideias e sentimentos reforçadores da submissão, alienação e resignação, como também em fatores que prejudicam a capacidade de enfrentamento de situações adversas. Evidencia-se que essas consequências da pobreza fazem parte de uma Ideologia de Submissão e Resignação presente em uma sociedade desigual como forma de manutenção de uma realidade opressora dos mais pobres em prol da permanência da concentração de riquezas nos mais ricos (Góis, 2012).

Nesse sentido, embora Sloan (2009, p. 227) afirme que "a Psicologia, sistematicamente, tornou a si mesma irrelevante para os debates na economia e na política", é justamente a centralidade da pobreza no campo da questão social e a convocação da ciência psicológica como disciplina promotora do bem-estar social (Dantas, Oliveira, \& Yamamoto, 2010) que a coloca frente a um dilema ético e práxico. Durante longo período, a Psicologia se manteve inerte, distanciada de caminhos que levassem a compreensão da questão social como expressão no cotidiano da vida social de todas as contradições advindas da ascensão da sociedade capitalista (Yamamoto, 2007). Essas contradições contribuem para a ocorrência de problemáticas sociais, políticas e econômicas responsáveis pela perpetuação da pobreza, pela manutenção da desigualdade e da exclusão social.

O desafio que se coloca é em que sentido a Psicologia poderá contribuir não mais com a disposição de referenciais teóricos e técnicos 
para a manutenção e reprodução do capital, mas sim, como campo de conhecimento capaz de denunciar as estratégias de domínio e controle dos grandes contingentes de pessoas que se constituem como força de trabalho explorada e submissa.

É, portanto, requerido à Psicologia o engajamento junto às ações políticas; a apropriação de saberes de outros campos; a efetivação de trabalhos em parceria com outras categorias profissionais, bem como a formulação de novos saberes coerentes com a realidade que se impõe (Oliveira \& Amorim, 2012). Tais aspectos inscrevem que a Psicologia deve enveredar por caminhos de reflexão e intervenção junto às problemáticas sociais para não tornar a si mesma irrelevante.

A análise da pobreza, enquanto fenômeno multidimensional, deve se fundamentar na observação de categorias que se distanciem da psicologização dos processos vividos em situações de privação. Ao contrário, inscreve-se a necessidade de que a Psicologia deve se posicionar, conforme afirma Oliveira e Amorim (2012, pp. 564-565), contra a “. . . estrutura de exploração que vitima e culpa os pobres, retira do Estado a responsabilidade pelas mazelas sociais e as atribui aos indivíduos, fragmenta as noções de coletividade" e destina aos sujeitos excluídos da distribuição da riqueza das nações o lugar de problema social.

Nesse sentido, a compreensão de bem estar deve se dar de modo amplo (Chiappero-Martinetti, 2000; Samman, 2007) não mais como conceito baseado na renda e na aquisição de bens de consumo, mas sim abordando questões pessoais e condições contextuais, estruturais, sociais e ideológicas. Lelli (2001) pontua que este conceito de bem estar deve se basear na crítica desenvolvida pela $\mathrm{AC}$ que problematiza o conceito de bem estar presente na Economia como baseado na renda e na aquisição de bens de consumo. Assim, o bem estar, tal como a pobreza, deve ser concebido como conceito multifacetado e complexo.

O Bem Estar Pessoal (BEP), parte de avaliações subjetivas e objetivas, abarcando tanto o bem estar subjetivo, como o psicológico (Ribeiro \& Cummins, 2008). O núcleo central do BEP é constituído dos conceitos básicos: satisfação global com a vida, felicidade e satisfação com os âmbitos da vida. Há, igualmente, um conjunto de núcleos periféricos que apresentam correlações positivas com essas categorias centrais acima identificadas, sendo representadas pela autoestima, percepção de controle, apoio social percebido, otimismo vital, entre outros (Casas, 2010). Tais conteúdos identificados no sujeito não são oriundos de um processo individual dissociado dos aspectos sociais. Ao contrário, entende-se que o que a pessoa pode fazer e ser, que são seus funcionamentos, como uma expressão no nível individual das possibilidades reais que a pessoa possui de ter mais bem estar, ou seja, de exercer a autonomia que o indivíduo é portador. $\mathrm{O}$ desafio que se coloca é em que sentido, diante das condições sociais, econômicas e políticas, os sujeitos de fato conseguem vivenciar este seu potencial autônomo quando, na verdade, estar excluído é concebido como um resíduo necessário à competitividade do mundo globalizado (Castel, 1997). Consoante com esta perspectiva, a Abordagem das Capacitações teria o bem estar como um dos seus objetos de análise juntamente com a pobreza, a qualidade de vida, a justiça e a desigualdade (Comim, 2008). Propõe-se, então, que sejam acrescidos, para a compreensão de Bem Estar Pessoal, os indicadores relacionados à saúde, à longevidade, à educação e às relações sociais (Chiappero-Martinetti, 2000), além das dimensões status socioeconômico, estresse psicológico e as atividades culturais (Lelli, 2001).

Assim, partindo desse apontamento, há também o compartilhamento, pelos moradores das periferias pobres, de questões políticas, econômicas e sociais comuns, além dos “. . . sistemas de relações e representações, os modos de apropriação do espaço físico-social, a identidade pessoal e social, a consciência, o sentido da comunidade e os valores e sentimentos aí implicados" (Góis, 2008, p. 83). No que concerne aos enfrentamentos da situação de pobreza, é importante a identificação do senso de comunidade como uma valiosa ferramenta, posto que permite considerar a expressão das interrelações entre os coletivos e as vivências pessoais. O Senso de comunidade refere-se a um conceito sócio-psicológico que 
enfatiza a experiência da comunidade, procurando compreender atitudes, sentimentos relacionamentos e interações entre as pessoas em um contexto comunitário (Elvas \& Moniz, 2010).

Nesse sentido, afirma-se como "o sentimento de que fazemos parte de uma rede de relacionamento de suporte mútuo, sempre disponível e da qual podemos depender" (Sarason, 1974, p. 1). Fazer parte da comunidade está relacionado à possibilidade do indivíduo de explorar seu entorno ambiental e comunitário, como também ter relações livres entre os vizinhos. É necessário, então, compreender como o sujeito em situação de pobreza exerce sua habilidade de buscar e realizar objetivos que são importantes e justos para si ou que tenham razões de sê-los (Alkire \& Deneulin, 2009) em sua dinâmica comunitária, pois o senso de comunidade também pode ser compreendido como constituinte do bem estar pessoal do sujeito e como um dos seus estados de ser e de fazer que constituem seus funcionamentos e capacitações.

Igualmente, é pertinente atentar para as implicações psicossociais negativas de uma vida em condições de pobreza que igualmente tem impacto no potencial de agenciamento do indivíduo pobre. Seguindo o entendimento da pobreza em uma perspectiva multidimensional, a pessoa empobrecida está submetida a práticas de opressão, que se constituem como fenômeno psicossocial e coletivo que resulta em diferentes formas de violência e sofrimento individual (Guzzo, 2010). Igualmente, reúnem-se diferentes estratégias de convencimento do pobre de sua incapacidade como estratégia de dominação e se ancoram na pobreza para garantir sua perpetuação. O sujeito pobre é concebido como inferior, instaurando um processo de estigmatização da pobreza (Moane, 2003; Narayan, 2000; Prilleltensky, 2003; Raditloaneng, 2009; Zavaleta, 2007). Cidade et al. (2012) abordam que há socialmente um conjunto de formas de reconhecimento da pessoa em situação de pobreza geralmente vinculado a aspectos depreciativos.

Identifica-se, assim, que para avaliar o impacto dessas práticas de opressão ao pobre deve-se verificar a existência dos sentimentos que surgem como consequência da estigmatização.
Compreende-se, portanto, que a vergonha e as práticas de humilhação estão relacionadas a uma identidade social de pobre constituída de um estigma, podendo ser resultado de práticas discriminatórias opressoras impetradas aos indivíduos pobres. Narayan (2000) enfatiza que geralmente as pessoas pobres estão submetidas a práticas de humilhação e à vergonha por conta do reconhecimento depreciativo. A vergonha e a humilhação causadas pela pobreza tem impacto na forma como o indivíduo desempenha suas atividades diárias. Resultam, assim, "no isolamento cada vez maior, como as pessoas sendo capazes de participar cada vez menos das cerimônias sociais e das tradições que outrora reuniam pessoas e ajudavam a criar e a manter os laços sociais entre os indivíduos" (Zavaleta, 2007, p. 2, tradução nossa). Dessa maneira, a vergonha e a humilhação causado pela pobreza poderia estar relacionado de forma negativa ao bem estar pessoal e ao senso de comunidade, interferindo de forma global na vida do indivíduo pobre.

Além da compreensão dessas práticas discriminatórias, é identificado que a vida em condições de pobreza contribui para o estabelecimento de experiências cotidianas de privação, abandono e agressão que reforçam a formação de conceitos explicativos sobre os fatos cotidianos como advindos de pouca sorte ou oriundos de forças divinas (Cidade, 2012). O fatalismo, neste sentido, configura-se como um fenômeno psicossocial manifesto pela interação entre as pessoas e um mundo que, permeado pelo funcionamento opressivo das estruturas macrossociais, apresenta-se como fechado e incontrolável (Martín-Baró, 1998).

As características do fatalismo, segundo proposto por Martín-Baró (1998), podem ser observadas pela manifestação de uma tríplice vertente ideacional, afetiva e comportamental, que congrega a concepção da vida como algo pré-determinado e fruto de uma vontade divina, resignação frente ao próprio destino, aceitação do sofrimento, pessimismo e resignação. Contudo, é valido ressaltar que o fatalismo não se refere a uma total apatia do sujeito diante do mundo. Pode expressar-se como um potencial de (re)ação diante de uma realidade que parece 
incontrolável (Lewis, 1969). Afinal, “com o passar dos dias, os recorrentes esforços frustrados em mudar o curso da vida acabam por criar, no imaginário dos indivíduos, um conjunto de leis, justificativas e modelos explicativos a fim de dar conta dessa realidade apresentada engessada" (Cidade, 2012, p. 112).

Consoante com esta prerrogativa, ressalta Marujo e Neto (2010, p. 519) que, ao trabalhar com populações desfavorecidas e marginais ao poder, é necessário estar atento às práticas implementadas e às teorias subjacentes,

... pelo ainda maior risco de criação de dependências e minorização das populações, as quais assumem, por regra, por expectativas antecipadas de apoio, e por óbvia resposta ao sistema que estimula dependências e fragilidades, a posição de vítimas.

Assim, deve-se expandir o entendimento da pobreza vinculada somente à perspectiva unidimensional monetária e à compreensão limitada da abordagem multidimensional referente a questões concretas. Isso permitirá a compreensão dos aspectos subjetivos da vida em privação e que acarretam limitações no exercício dos sujeitos de seu potencial inventivo e de reconstrução da realidade. É necessário considerar os vários elementos que incidem sobre a realidade de pobreza, auxiliando as elaborações no campo psicológico que anunciam um movimento de libertação (Guzzo \& Lacerda, 2009; Martín-Baró, 1998; Nepomuceno, Ximenes, Cidade, Mendonça, \& Soares, 2008; Ximenes \& Góis, 2010), tanto das concepções até então difundidas sobre o que é a pobreza, suas causas e consequências psicológicas, como sobre as alternativas possíveis tendo em vista a construção de um conhecimento crítico a favor dos oprimidos e comprometido ética e politicamente.

\section{Considerações Finais}

Conclui-se que é imprescindível à Psicologia e a áreas afins se apropriarem do fenômeno pobreza em seus múltiplos sentidos. Há a necessidade de perceber a pobreza de forma crítica e multidimensional, entendo-a como resultado de diversos fatores nos quais a renda é um deles.
Identifica-se, assim, que as políticas de enfrentamento à pobreza reduziram-se à privação de renda, reproduzindo concepções acríticas e monetárias de pobreza. Assim, a Abordagem Multidimensional surge como contraponto a essa visão, ampliando a sua compreensão e relacionando-a a especificidades pessoais, sociais e culturais do sujeito. No entanto, em sua perspectiva prática, a Abordagem das Capacitações ainda é portadora de limitações referentes as dimensões psicossociais apresentadas, sendo necessário auxílio da Psicologia para compreensão crítica e ampliada desse fenômeno.

Assim, cabe a Psicologia atuar no desvelamento dessa rede de opressão e no fortalecimento das pessoas inseridas nessa realidade, acrescentado os conceitos de bem estar pessoal, de senso de comunidade, de discriminação e de fatalismo na compreensão multidimensional desse fenômeno. É importante ressaltar que essas categorias não se referem a uma tentativa de psicologização da pobreza, mas de entendimento da relação do indivíduo pobre com uma realidade desigual e opressora. Por conseguinte, considerar a existência de elementos psicossociais como oriundos da capacidade do sujeito de fornecer cadeias explicativas singulares para suas experiências de privação implica em um duplo processo: na ênfase atribuída à capacidade do sujeito de externalizar os elementos subjetivos da vida em condições de pobreza e na necessária incorporação desses elementos nos âmbitos de investigação e discussão da pobreza.

\section{Referências}

Accorssi, A., Scarparo, H., \& Guareschi, P. (2012). A naturalização da pobreza: Reflexões sobre a formação do pensamento social. Psicologia \& Sociedade, 24(3), 536-546. doi:10.1590/S010271822012000300007

Alkire, S. (2005). Why the capability approach? Journal of Human Developmen, 6(1), 115-134.

Alkire, S. (2007). The missing dimensions of poverty data: An introduction. Oxford Poverty \& Human Development Initiative (OPHI Working Paper No. 00). Retrieved September 16, 2011, from http://www.ophi.org.uk/workingpaper-number-0/ 
Alkire, S., \& Deneulin, S. (2009). The human development and capability approach. In S. Deneulin $\&$ L. Shahani (Eds.), An introduction to the human development and capability approach (Vol. 22). London: Earthscan.

Andrade, M. R. (2011). A concepção de pobreza através das diferentes abordagens avaliatórias de bem-estar e sua implicação para elaboração de políticas públicas (Trabalho de conclusão de Curso de Economia, Universidade Federal do Rio Grande do Sul, Porto Alegre, RS, Brasil).

Avila, R. P., Bagolin, I. P., \& Comin, F. V. (2012). Heterogeneidade individuais versus intensidade da pobreza em Porto Alegre - RS. Revista Economia, 13(2), 447-463.

Barros, R. P., Carvalho, M., \& Franco, S. (2007). A queda recente da desigualdade de renda no Brasil. Rio de Janeiro, RJ: Instituto de Pesquisa Econômica Aplicada.

Brasil comemora redução da pobreza extrema. (2012). Recuperado em $1^{\circ}$ de julho, 2013, de http://rf-brasil.jusbrasil.com.br/politica/103854322/ brasil-comemora-reducao-da-pobreza-extrema

Casas, F. (2010). El bienestar personal: su investigación en la infancia y la adolescencia. Encuentros en Psicología Social, 5(1), 85-101.

Castel, R. (1997). As armadilhas da exclusão. In R. Castel, L. E. W. Wanderley, \& M. Belfiore-Wanderley, Desigualdade e a questão social. São Paulo, SP: Educ.

Cidade, E. C. (2012). Juventude em condições de pobreza: Modos de vida e fatalismo (Dissertação de mestrado, Programa de Pós-Graduação em Psicologia, Universidade Federal do Ceará, Fortaleza, CE, Brasil).

Cidade, E. C., Moura, J. F., Jr., \& Ximenes, V. M. (2012). Implicações psicológicas da vida em condições de pobreza para o povo latino-americano. Psicologia \& Argumento, 30(68), 87-98.

Chiappero-Martinetti, E. (2000). A multidimensional assessment of well-being based on Sen's functioning approach. Rivista Internazionale di Scienze Sociali, 2, 207-239.

Chiappero-Martinetti, E., \& Moroni, S. (2007). An analytical framework for conceptualizing and re-examining the capability approach. The Journal of Socio-Economics, 26, 360-375.

Cohen, A. G. (1996). Igualdad de qué? Sobre el bienestar, los bienes y las capacidades. In M. C.
Nussbaum \& A. Sen (Eds.), La calidad de vida. México, DF: Fondo de Cultura Económica.

Comim, F. V. (2008). Operationalizing Sen's capability approach. In F. V Comim, M. Qizilbash, $\&$ S. Alkire, The capability approach: Concepts, measures and applications. Nem York: Cambridge Press.

Comim, F. V., \& Bagolin, I. P. (2002). Aspectos qualitativos da pobreza no Rio Grande do Sul. Ensaios FEE, 23, 467-490.

Crespo, A. P. A., \& Gurovitz, E. (2000). A pobreza como fenômeno multidimensional. RAE-Eletrônica, 1(2), 1-12.

Dantas, C. M. B., Oliveira, I. F., \& Yamamoto, O. H. (2010). Psicologia e pobreza no Brasil: Produção de conhecimento e atuação do psicólogo. Psicologia \& Sociedade, 22(1), 104-111.

Elvas, S., \& Moniz, M. J. V. (2010). Sentimento de comunidade, qualidade e satisfação de vida. Análise Psicológica, 3(28), 451-464.

Góis, C. W. L. (2008). Saúde comunitária: Pensar e fazer. São Paulo, SP: Hucitec.

Góis, C. W. L. (2012). Psicologia Clínico Comunitária. Fortaleza, CE: Banco do Nordeste.

Guzzo, R. S. L. (2010). Da opressão à libertação: Uma perspectiva urgente para a Psicologia - A conclusão de um projeto, a abertura de perspectivas. In R. S. L Guzzo \& F. Lacerda Jr. (Eds.), Psicologia \& Sociedade: Interfaces no debate sobre a questão social (Cap. 1). Campinas, SP: Alínea.

Guzzo, R. S. L., \& Lacerda, F. A., Jr. (Eds.). (2009). Psicologia Social para América Latina: O resgate da Psicologia da Libertação. Campinas, SP: Alínea.

Kerstenetsky, C. L. (2000). Desigualdade e pobreza: Lições de Sen. Revista Brasileira de Ciências Sociais, 15(42), 113-122.

Lacerda, F. C. C. (2009). A pobreza na Bahia sobre o prisma multidimensional: Uma análise baseada na Abordagem das Necessidades Básicas e na Abordagem das Capacitações (Dissertação de mestrado, Programa de Pós-Graduação em Economia, Universidade Federal de Uberlândia, MG, Brasil).

Laderchi, C., Saith, R., \& Stewart, F. (2003). Does it matter that we don't agree on the definition of poverty? A comparison of four approaches 
(QEH Working Paper Series No. 107). Retrieved February 11, 2011, from http://www3.qeh. ox.ac.uk/pdf/qehwp/qehwps107.pdf

Lelli, S. (2001). Factor analysis vs. Fuzzy sets theory: Assessing the influence of different techniques on sen's functioning approach (Center for Economics Studies Discussion Paper Series 01.21). Retrieved September 16, 2012, from http://www.econ.kuleuven.be/eng/ew/discussionpapers/Dps01/Dps0121.pdf

Lewis, O. (1969). The culture of poverty. In D. Moynihan, On understanding poverty: Perspectives from the Social Scienses. New York: Basic Books.

Martín-Baró, I. (1998). Psicología de la liberación. Madrid, España: Trotta.

Marujo, H. A., \& Neto, L. M. (2010). Psicologia Comunitária Positiva: Um exemplo de integração paradigmática com populações de pobreza. Análise Psicológica, 28(3), 517-525.

McKinley, T. (2008). O que é pobreza? Boa pergunta. One Pager. Centro de Internacional de Pobreza (CIP Publicação No. 26). Recuperado em 24 de agosto, 2012, de http://www.ipc-undp.org/pub/ port/IPCOnePager26.pdf

Ministério do Desenvolvimento Social e Combate à Fome. (2012). Plano Brasil sem miséria. Conheça o Plano. Recuperado em 14 de junho, 2013, de http://www.brasilsemmiseria.gov.br/apresentacao/conheca-o-plano

Ministério do Desenvolvimento Social e Combate à Fome. (2013). Bolsa Família. Recuperado em 14 de junho, 2013, de http://www.mds.gov.br/ bolsafamilia

Moane, B. (2003). Bridging the personal and the political: Practices for a liberation psychology. American Journal of Community Psychology, 31(1-2), 91-101.

Moura, J. F., Jr. (2012). Reflexões sobre a pobreza a partir da identidade de pessoas em situação de rua de Fortaleza (Dissertação de mestrado, Programa de Pós-Graduação em Psicologia, Universidade Federal do Ceará, Fortaleza, CE, Brasil).

Narayan, D. (2000). Voices of the poor-Can anyone hear us? Washington, DC: The World Bank.

Nepomuceno, L. B., Ximenes, V. M., Cidade, E. C., Mendonça, F. W O., \& Soares, C. A. (2008). Por uma psicologia comunitária como práxis de libertação. Psico, 39(4), 456-464.
Oliveira, I. F., \& Amorim, K. M. O. (2012). Psicologia e política social: $\mathrm{O}$ trato à pobreza como "sujeito psicológico". Psicologia Argumento, 30(70), 559-566.

Organização das Nações Unidas no Brasil. (2011). Número de trabalhadores pobres vivendo com menos de dois dólares por dia caiu 24\% em 19 anos, diz OIT. Recuperado em 10 de maio, 2012, de http://www.onu.org.br/numero-de-trabalhadores-pobres-vivendo-com-menos-de-dois-dolares-por-dia-caiu-24-em-19-anos-diz-oit/

Picolotto, V. C. (2006). Pobreza e desenvolvimento sob os paradigmas da renda e das capacitações: Uma aplicação para a Grande Porto Alegre através dos indicadores fuzzy (Dissertação de mestrado, Programa de Pós-Graduação em Economia, Universidade Federal do Rio Grande do Sul, Porto Alegre, RS, Brasil).

Prilleltensky, I. (2003). Understanding, resisting, and overcoming oppression: Toward psychopolitical validity. American Journal of Community Psychology, 31(1-2), 195-201.

Programa das Nações Unidas para o Desenvolvimento. (2010). Relatório de Desenvolvimento Humano. A verdadeira riqueza das nações: Vias para o desenvolvimento humano. Recuperado em 10 de novembro, 2010, de http://hdr.undp.org/en/ media/HDR_2010_PT_Complete_reprint.pdf

Raditloaneng, W. N. (2009). Socialization as a factor in poverty identity formation: A pilot casa study of the poor in selected areas of Botswana. Convergence, 42(1), 77-93.

Ribeiro, P. J., \& Cummins, R. (2008). O bem-estar pessoal: Estudo de validação da versão portuguesa da escala. In I. Leal, J. Pais-Ribeiro, I. Silva, \& S. Marques (Eds.), Actas do $7^{\circ}$ Congresso Nacional de Psicologia da Saúde (pp. 505-508). Lisboa, Portugal: Instituto Superior de Psicologia Aplicada.

Samman, E. (2007). Psychological and subjetive wellbeing: A proposal for a internationally comparable indicators. (OPHI Working Paper Series 05). Retrieved September 16, 2011, from http:// www.ophi.org.uk/wp-content/uploads/OPHI-wp05.pdf

Sarason, S. (1974). The perception and conception of a community. In The psychological sense of community: Prospects for a community psychology (pp. 130-160). San Francisco, CA: JosseyBass. 
Sen, A. K. (1980). Equality of what? In The Tanner lectures on human values (Vol. 1, pp. 197-220). Cambridge, UK: Cambridge UniversityPress.

Sen, A. K. (1996). Capacidad y bienestar. In M. C. Nussbaum \& A. K. Sen (Eds.), La calidad de vida. México, DF: Fondo de Cultura Económica.

Sen, A. (2000). Desenvolvimento como liberdade. São Paulo, SP: Companhia das Letras.

Sloan, T. (2009). Globalização, pobreza e justiça social: Papéis para os psicólogos. In R. S. L Guzzo \& F. Lacerda Jr., Psicologia Social para a América Latina: O resgate da Psicologia da Libertação. São Paulo, SP: Alínea.

Soares, S. S. D. (2009). Metodologias para estabelecer a linha de pobreza: Objetivas, subjetivas, relativas, multidimensional. Rio de Janeiro, RJ: Instituto Econômico de Pesquisa Aplicada.

Ximenes, V. M., \& Gois, C. W. L. (2010). Psicologia comunitária: Uma práxis latino-americana. In R. S. L Guzzo \& F. Lacerda Jr. (Eds.), Psicologia \& Sociedade: Interfaces no debate sobre a questão social. Campinas, SP: Alínea.
Yamamoto, O. H. (2007). Políticas sociais, "terceiro setor" e "compromisso social": Perspectivas e limites do trabalho do psicólogo. Psicologia \& Sociedade, 19(1), 30-37. doi:10.1590/S010271822007000100005

Zavaleta, D. R. (2007). The ability to go about without shame: A proposal for Internationally Comparable Indicators (OPHI Working Paper 03). Retrieved September 16, 2011, from http:// www.ophi.org.uk/working-paper-number-03/
Recebido: 09/08/2013

$1^{a}$ revisão: $15 / 11 / 2013$ Aceite final: 08/12/2013 